\title{
Evaluation of Real Time Cell Proliferation, Anti- Inflammatory and Wound Healing Potential of Helenalin on HaCaT Keratinocytes Treated with Lipopolysaccharide Stimulated Monocytes
}

\author{
S. N. YUKSEL, M. DIKMEN ${ }^{1 *}$ AND Z. CANTURK ${ }^{2}$
}

Ministry of Health, Turkish Medicines and Medical Devices Agency, Ankara, ${ }^{1}$ Faculty of Pharmacy, Department of Pharmacology, ${ }^{2}$ Department of Pharmaceutical Microbiology, Anadolu University 26210 Eskisehir, Turkeya

Yuksel et al.: Cell Proliferation, Anti-Inflammatory and Wound Healing Potential of Helenalin

\begin{abstract}
Arnica montana, of the family Asteraceae, is used for its anti-inflammatory and wound healing properties, especially for bruises, tissue injuries and other traumas. However, its cellular and molecular mechanisms are not yet fully known. Its main active ingredient is helenalin, a sesquiterpene lactone, known as one of the main active ingredients of Asteraceae species. The aim of this study was to investigate cell proliferation, wound healing and anti-inflammatory activity of helenalin on human keratinocyte cells treated with lipopolysaccharide stimulated human monocytic cell line. Human keratinocyte cells were treated with different helenalin concentrations $(0.095-50 \mu \mathrm{M})$ to determine toxic and nontoxic concentrations. Then, the effects of nontoxic $(0.02$ and $0.2 \mu \mathrm{M})$ and toxic $(2 \mu \mathrm{M})$ helenalin concentrations on human keratinocyte cell proliferation and migration were determined using the real time cell analysis system. The scratch assay was performed to determine wound healing activity and supernatants were collected to determine the effects of helenalin on cytokine levels of human keratinocyte cells under inflammatory and non-inflammatory conditions. Under inflammatory conditions, 0.02 and $0.2 \mu \mathrm{M}$ helenalin increased keratinocyte proliferation and induced the most wound healing and anti-inflammatory activity in human keratinocyte cells. Cell proliferation and migration, wound healing and anti-inflammatory effects were higher in cells exposed to $0.02 \mu \mathrm{M}$ helenalin than $0.2 \mu \mathrm{M}$. Helenalin has been found to decrease the production of inflammatory cytokines, especially under inflammatory conditions and increase wound closure by increasing cell proliferation and migration.
\end{abstract}

Key words: Helenalin, wound healing, anti-inflammatory effect, cell proliferation, migration

Wound healing is a process involving hemostasis, inflammation, proliferation, restructuring and maturation initiated to restore the anatomical and physiological features of skin with impaired integrity ${ }^{[1,2]}$. It is a complex process involving not only damaged cells, but also adjacent cells and fibroblasts, blood vessels, inflammatory cells and leukocytes recruited to the affected environment ${ }^{[3,4]}$.

Arnica montana, discovered by Linnaeus in 1753, is a member of the Asteraceae family, known for its antiinflammatory properties ${ }^{[5,6]}$. It is rich in sesquiterpene lactones, flavonoids, essential oils, terpenoids and phenolic acids ${ }^{[7]}$. Topical tinctures and ointments of A. montana have been used for the treatment of hematomas, bruises, sprains, rheumatoid conditions, superficial inflammations of the skin and mouth,

*Address for correspondence

E-mail: mirisd@anadolu.edu.tr burns, cerebral disorders, skin cancer and insomnia ${ }^{[7,8]}$. Suggested components responsible for the effects of the plant are sesquiterpene lactones such as helenalin, 11- $\alpha$, 13-dihydrohelenalin and chamissonolide and their short chain esters ${ }^{[9-11]}$.

Helenalin is a sesquiterpene lactone with antiinflammatory, antibacterial, anti-parasitic and anticancer activities and is found in Arnica montana L. ${ }^{[12,13]}$. It is found in the aboveground parts of the plant,

\footnotetext{
This is an open access article distributed under the terms of the Creative Commons Attribution-NonCommercial-ShareAlike 3.0 License, which allows others to remix, tweak, and build upon the work non-commercially, as long as the author is credited and the new creations are licensed under the identical terms
}

Accepted 14 March 2021 Revised 18 February 2021

Received 21 September 2020 Indian J Pharm Sci 2021;83(2):219-229 
which grows naturally in the mountainous regions of Europe ${ }^{[14]}$. It has been suggested that helenalin selectively inhibits nuclear factor kappa light chain

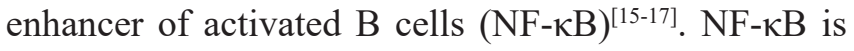
known to mediate pro inflammatory responses and can promote tumorigenesis by controlling multiple tumor related processes such as inflammation, proliferation, angiogenesis and metastasis. Targeting the p50/p65 heterodimer, helenalin may be considered a more specific NF- $\mathrm{KB}$ inhibitor than compounds which inhibit upstream proteins such as inhibitor of nuclear factor kappa B kinase subunit alpha (I $\kappa K \alpha$ ) and $\mathrm{I} \kappa \mathrm{K} \alpha / \beta$, playing essential roles in other biochemical processes. Helenalin has been shown to exert strong anti-inflammatory and antiprotozoal effects and to suppress the proliferation of cancer cells. The ability of helenalin to selectively target the p50/p65 transcription factor heterodimer, the most downstream proteins in the NF- $\mathrm{KB}$ signaling pathway, can be regarded as its most important action ${ }^{[18]}$.

Human keratinocyte cells (HaCaT cells) (human, adult, low calcium, high temperature) are immortalized human keratinocyte cells and are frequently used in studies investigating epidermal homeostasis and its pathophysiology ${ }^{[19,20]}$. HaCaT cells maintain normal keratinocyte morphology and epidermal differentiation capacity and can release cytokines and chemokines ${ }^{[21]}$. The HaCaT cell line is widely used to investigate the molecular mechanisms of skin inflammation due to its ability to induce Interleukin 1 beta (IL-1 $\beta$ ) and Tumor necrosis factor alpha (TNF- $\alpha$ ) expression upon exposure to lipopolysaccharide (LPS) ${ }^{[22]}$. Keratinocytes actively contribute to inflammation, especially by releasing pro inflammatory cytokines, chemokines, growth factors, matrix metalloproteinases (MMPs) and proteases. Therefore, keratinocytes are not only primary sensors of stressful conditions but also significant players in the extremely complex immune response in the $\operatorname{skin}^{[23]}$.

Human monocytic cell line (THP-1) is a spontaneously immortalized monocyte like cell line and it has been one of the most frequently used lines in the investigation of monocyte and macrophage function ${ }^{[24-26]}$. Monocytes and macrophages are important players in innate immunity, involved in phagocytosis and the release of inflammatory chemokines and reactive oxygen species (ROS). LPS is the major component of Gram negative bacteria cell walls and can cause an acute inflammatory response by triggering the release of a vast number of inflammatory cytokines in various cell types. LPS is widely recognized as a potent activator of monocytes/ macrophages ${ }^{[27]}$. THP-1 cells possess regulatory proteins that initiate inflammation upon stimulation by $\operatorname{LPS}^{[28]}$.

In this study, we investigated the cell proliferation, antiinflammatory and wound healing effects of helenalin on HaCaT keratinocytes treated with an LPS stimulated THP1 cell line.

\section{MATERIALS AND METHODS}

\section{Cell lines and culture conditions:}

Human skin keratinocytes, HaCaT cells (CLS no: 300493, Almanya) were supplied by Professor Dr. Arzu Onay Besikci, Ankara University. THP-1 (ATCC® TIB-202 ${ }^{\mathrm{TM}}$, USA) were obtained from the American type culture collection. HaCaT cells were grown in Roswell Park Memorial Institute (RPMI-1640) medium supplemented with $10 \%$ fetal bovine serum (FBS), 2 $\mathrm{ml} \mathrm{L-glutamine}$ and $1 \%$ penicillin/streptomycin at $37^{\circ}$ in a humidified incubator with a $5 \%$ carbon dioxide $\left(\mathrm{CO}_{2}\right)$ atmosphere. The THP-1 human monocyte cells were grown in RPMI-1640 medium supplemented with $10 \%$ FBS, $1 \%$ penicillin-streptomycin and $0.37 \%$ mercaptoethanol at $37^{\circ}$ in a $5 \% \mathrm{CO}_{2}$ and $95 \%$ relative humidity incubator. HaCaT and THP-1 cells were stained with trypan blue solution and counted with a cell counter (Cedex XS, Innovatis, USA) to determine the appropriate cell numbers before every experiment.

\section{Preparation of helenalin concentrations:}

Helenalin (Santa Cruz Biotechnology, sc-218579, USA), a specific NF-kB inhibitor, was dissolved in dimethyl sulfoxide (DMSO) to obtain a stock solution $(100 \mathrm{mM})$ and was aliquoted and stored at $-20^{\circ}$. The stock solution was diluted to the required concentrations in the cell medium. Cultures with $80 \%$ cell confluence were used in cell culture experiments.

\section{Lipopolysaccharide (LPS) inflammation model:}

THP-1 cells are the most commonly used cell lines in the investigation of the functions of monocytes and macrophages and the evaluation of anti-inflammatory effect $^{[26]}$. The bacterial endotoxin LPS is a common inducer of pro inflammatory properties. For stimulation of THP-1 cells, $6 \times 10^{5}$ cells were seeded in $25 \mathrm{~cm}^{2}$ flask and cells were treated with $100 \mathrm{ng} / \mathrm{ml}$ of LPS from Gram negative bacteria Escherichia coli (L4391, Sigma-Aldrich, St. Louis, MO, USA) in the medium for $4 \mathrm{~h})^{[28]}$. Cells were then incubated for $4 \mathrm{~h}$ at $37^{\circ}$ in $5 \% \mathrm{CO}_{2}$ and $95 \%$ relative humidity, after which cells 
were centrifuged and supernatants were collected and stored at $-20^{\circ}$. To simulate inflammatory conditions, supernatants (in the article to express as the medium with LPS) were used in real time cell proliferation, migration and wound healing experiments.

Cytotoxicity was measured using a colorimetric assay in 96 well plates with a solution of WST1 or 2-(4-iodophenyl)-3-(4-nitrophenyl)-5-(2,4disulfophenyl)-2H-tetrazolium monosodium salt. In this method, the reduced tetrazolium salt is water soluble ${ }^{[29]}$. HaCaT cells were seeded in 96 well plates at a density of $3 \times 10^{3}$ cells per well. After $24 \mathrm{~h}, 100 \mu \mathrm{l}$ freshly prepared helenalin concentrations $(50,25,12.5$, $6.25,3.125,1.56,0.78,0.39,0.19$ and $0.095 \mu \mathrm{M})$ were added to each well. After 24 and $48 \mathrm{~h}$ incubation, $10 \mu \mathrm{l}$ WST-1 solutions were added to each well and plates were incubated for $3 \mathrm{~h}$. The absorbances were measured at $450 \mathrm{~nm}$ using a Cytation 3 cell imaging multi-mode reader (Bio-Tek) according to the WST-1 kit protocol (Cat. no: 11644807001, Roche). The measured absorbance directly correlates with the number of viable cells. Cell viability rates were expressed as a percentage of the solvent control value $(0.1 \%$ DMSO in the medium $)^{[30,31]}$.

\section{Cell proliferation analysis with xCELLigence real time cell analysis (RTCA) system:}

The kinetics of cell proliferation were monitored with an xCELLigence real time cell analysis (RTCA) dual purpose (DP) instrument (Roche, Mannheim, Germany), which measures electrical impedance across inter digitated micro electrodes incorporated on the bottom of tissue culture e-plates. Electrical impedance indicates the cell index (CI) value and provides quantitative information about the condition of the cells, involving cell number, viability and morphology [32-34].

Helenalin concentrations to be used in the real time $\mathrm{HaCaT}$ cell analysis system were determined by the WST-1 method. We selected 2, 0.2 and $0.02 \mu \mathrm{M}$ concentrations, which included concentrations that were non cytotoxic. The background of the e-plates was measured using $100 \mu \mathrm{l}$ medium in the RTCA DP station. Then, $100 \mu \mathrm{l}$ of $\mathrm{HaCaT}$ cell suspensions were added (10 000 cells/well). Plates were incubated for $30 \mathrm{~min}$ at room temperature and e-plates were placed into the instrument. Impedance was measured at $1 \mathrm{~h}$ intervals. Approximately $24 \mathrm{~h}$ after seeding, when the cells were in the log phase growth the instrument was paused and $100 \mu 1$ medium was carefully removed from each well. Then the cells were treated with $100 \mu \mathrm{l}$ of medium containing different helenalin concentrations. For experimental groups, 2, 0.2 and $0.02 \mu \mathrm{M}$ helenalin concentrations were diluted using either the $\mathrm{HaCaT}$ cell medium or medium of THP-1 cells stimulated with LPS. (As e-plate wells previously contained $100 \mu \mathrm{l}$ medium, $2 \mathrm{x}$ concentrations were prepared.) A $0.1 \%$ DMSO solution was used as a negative control and stimulated medium (with LPS) was used as a positive control. Impedance monitoring continued for another $48 \mathrm{~h}$. The electrical impedance, the dimensionless parameter CI, was analysed by RTCA connected software of the RTCA DP system ${ }^{[35,36]}$.

\section{Wound healing with scratch assay:}

The scratch assay is considered a standard in vitro wound healing assays ${ }^{[37]}$. A cell free area in monolayer culture is created in the form of a straight line using mechanical, thermal or chemical destruction and the subsequent expansion of the cell population on the disturbed surface is measured ${ }^{[38]}$.

The spreading and migration capabilities of $\mathrm{HaCaT}$ keratinocyte cells were assessed using a scratch wound healing assay. The cells were seeded into 24 well plates at a concentration of $1 \times 10^{5}$ cells per well and cultured in medium to nearly confluent cell monolayers. After aspirating the medium, a linear wound was generated in the monolayer with a sterile $100 \mu \mathrm{l}$ plastic pipette tip. Any cellular debris was removed by washing the wells with phosphate buffer saline (PBS). For experiment groups, 0.2 and $0.02 \mu \mathrm{M}$ helenalin concentrations were prepared using either the $\mathrm{HaCaT}$ cell medium or medium of THP-1 cells stimulated with LPS. These solutions were added to the wells and incubated for $48 \mathrm{~h}$ at $37^{\circ}$ with $5 \% \mathrm{CO}_{2}$. The negative control was $0.1 \%$ DMSO containing medium and the positive control was stimulated medium (+LPS). The wells were photographed at $48 \mathrm{~h}$. Three representative images from each well of the scratched areas under each condition were photographed with a Leica DM 300 inverted microscope. Relative migration of the cells was estimated by analysing the images with the Leica application suite (LAS) image analysis programme and measuring the scratched area ${ }^{[39]}$. The data were analysed using GraphPad Prism 6.0. The experiments were performed at least in duplicate. After photos were taken, supernatants were collected at $48 \mathrm{~h}$, aliquoted and stored at $-20^{\circ}$ for cytokine measurement by flow cytometry. 
Cell migration analysis using the $x$ CELLigence real time cell analysis system:

Cell migration and invasion assays were conducted with RTCA DP using Cell Invasion and Migration plate (CIM-16) plates containing microelectronic sensors connected to the underside of the plate ${ }^{[40]}$. CIM plates are a two chamber system, consisting of a micro porous membrane that allows cells to pass. Cells are plated in the upper chamber with a serum free medium. Migratory cells in the upper chamber can cross the porous membrane and tend to move from the upper chamber with serum free medium to the lower chamber with serum. Cells with fast migration pass to the lower chamber and multiply and the signal is received by the device during the transition. Cells that do not migrate remain in the upper chamber and there is no signal detection.

For the migration assays, the wells of the bottom chamber were filled with $160 \mu \mathrm{l}$ of $10 \%$ serum containing growth medium and the top and bottom parts of the CIM 16 plates were assembled. After the addition of $20 \mu \mathrm{l}$ serum free growth medium to the top chamber wells, the assembled CIM plates were allowed to stabilize for $1 \mathrm{~h}$ in an incubator. After the incubation, the $\mathrm{HaCaT}$ cells were seeded at a density of $1 \times 10^{4}$ density cells per well into the top chambers of CIM plates in $80 \mu \mathrm{l}$ of serum free media, then $100 \mu 1$ of helenalin solutions were added (according to the result of the cell proliferation assay, 0.2 and $0.02 \mu \mathrm{M}$ helenalin were prepared with the medium of THP-1 cells stimulated with LPS). The stimulated medium (+LPS) was used as a control group. After stabilizing the CIM plates for $30 \mathrm{~min}$ at room temperature, the chamber was loaded into the RTCA DP machine and software was set to collect impedance data, reported as CI values, once every $10 \mathrm{~min}$ for $24 \mathrm{~h}^{[32,41]}$.

\section{Measurement of cytokines using flow cytometry:}

The cytokine (IL-1 $\beta$, Interleukin 6 (IL-6), Interleukin 8 (IL-8) and TNF- $\alpha$ ) levels were determined using the Becton Dickinson (BD) human inflammatory kit procedure (BD ${ }^{\mathrm{TM}}$ Cytometric Bead Array kit (CBA), $\mathrm{BD}$ 551811). The HaCaT cell culture supernatants were obtained at the end of the $48 \mathrm{~h}$ scratch assay. CBA analysis was conducted according to the kit procedure by using FCAP array in the BD Accuri C6 flow cytometer ${ }^{[42,43]}$.

\section{Statistical analysis:}

Statistical analysis of the results was performed using one way analysis of variance (ANOVA) and Tukey's post hoc test via GraphPad Prism 6.0 software (GraphPad Campany, San Diego). The results are the means of three independent experiments expressed as mean \pm standard deviation. $p$ values represent the significance of the results compared to the control group (n.s; $p>0.05, * p<0.05, * * p<0.01, * * * p<0.001$ and $* * * * \mathrm{p}<0.0001)$.

\section{RESULTS AND DISCUSSION}

Higher concentrations of helenalin showed significant cytotoxic effects in $\mathrm{HaCaT}$ cells. Cell viability was significantly decreased at $\geq 3.125 \mu \mathrm{M}$ concentrations of helenalin at $24 \mathrm{~h}(\mathrm{p}<0.001 * * *, \mathrm{p}<0.0001 * * * *)$ (fig. 1A). At the $48^{\text {th }} \mathrm{h}$, the $\mathrm{HaCaT}$ cell viability was significantly decreased between $0.78-50 \mu \mathrm{M}$ concentrations of helenalin. At $\geq 3.125 \mu \mathrm{M}$, in particular, cell viabilities were reduced by at least $50 \%$ compared to the control group at $48 \mathrm{~h}\left(\mathrm{p}<0.001^{* * *}\right)$ (fig. 1B).

The RTCA DP indirectly detects the cell number by measuring the electrical impedance and generates real time data by maintaining this measurement at desired intervals for days. The values obtained by the system are calculated as a unit less CI value.
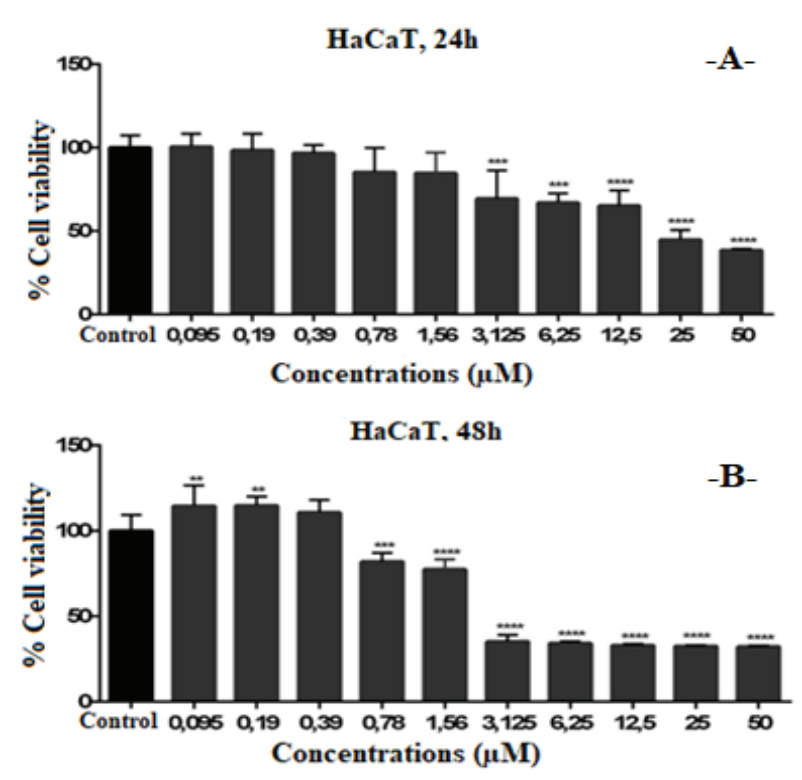

Fig. 1: The cells were treated with different concentrations of helenalin for $24 \mathrm{~h}$ (A) and $48 \mathrm{~h}$ (B) and percentage cell viability was determined from WST-1 results. Results are expressed as mean \pm standard deviation $(n=8)$ and the means of three independent experiments, $* * p<0.01, * * * p<0.001$ and $* * * * \mathbf{p}<0.0001$ were considered to be significant compared to control (0.1\% DMSO) group 
Real time based CI plots of the effect of 2, 0.2 and $0.02 \mu \mathrm{M}$ helenalin on $\mathrm{HaCaT}$ cells treated with/without LPS stimulated THP-1 cells we selected according to WST- 1 results were obtained by the RTCADP for 24 and $48 \mathrm{~h}$. The curves of HaCaT cell proliferation are seen in fig. 2 and fig. 3. After helenalin application, the highest cell proliferative effects were observed at 0.02 and $0.2 \mu \mathrm{M}$ helenalin treated with LPS stimulated monocytes at $24 \mathrm{~h}$. At these concentrations, cell proliferation increased compared to the medium control (solvent control of $0.1 \%$ DMSO) and positive control (LPS stimulated monocytes). However, at a concentration of $2 \mu \mathrm{M}$ helenalin with and without LPS stimulated monocytes, HaCaT cell proliferation decreased depending on the time and compared to other helenalin concentrations and the medium control (fig. 2). After helenalin application, the highest cell proliferative effects were observed at 0.2 and $0.02 \mu \mathrm{M}$ helenalin treated with LPS stimulated monocyte medium at 48 h. At these concentrations, cell proliferation increased compared to the medium and LPS controls. However, at $2 \mu \mathrm{M}$ helenalin with and without LPS stimulated monocyte medium, $\mathrm{HaCaT}$ cell proliferation decreased during the first $24 \mathrm{~h}$ and cells had died, depending on the cytotoxicity of the helenalin concentration (fig. 3). Similarly, $2 \mu \mathrm{M}$ helenalin demonstrated cytotoxicity in the WST results, especially at $48 \mathrm{~h}$. Using CI values, the slope values of helenalin concentrations were calculated in HaCaT cells using the RTCA 1.2.1 software at $24 \mathrm{~h}$. As shown in fig. 4, at the 0.2 and $0.02 \mu \mathrm{M}$ helenalin concentration with LPS conditioned medium significantly increased $\mathrm{HaCaT}$ cell proliferation $(\mathrm{p}<0.0001 * * * *)$.

The spreading and migration capabilities of HaCat keratinocyte cells were assessed using a scratch wound healing assay, which measures the expansion of a cell population on surfaces. We first analysed helenalin

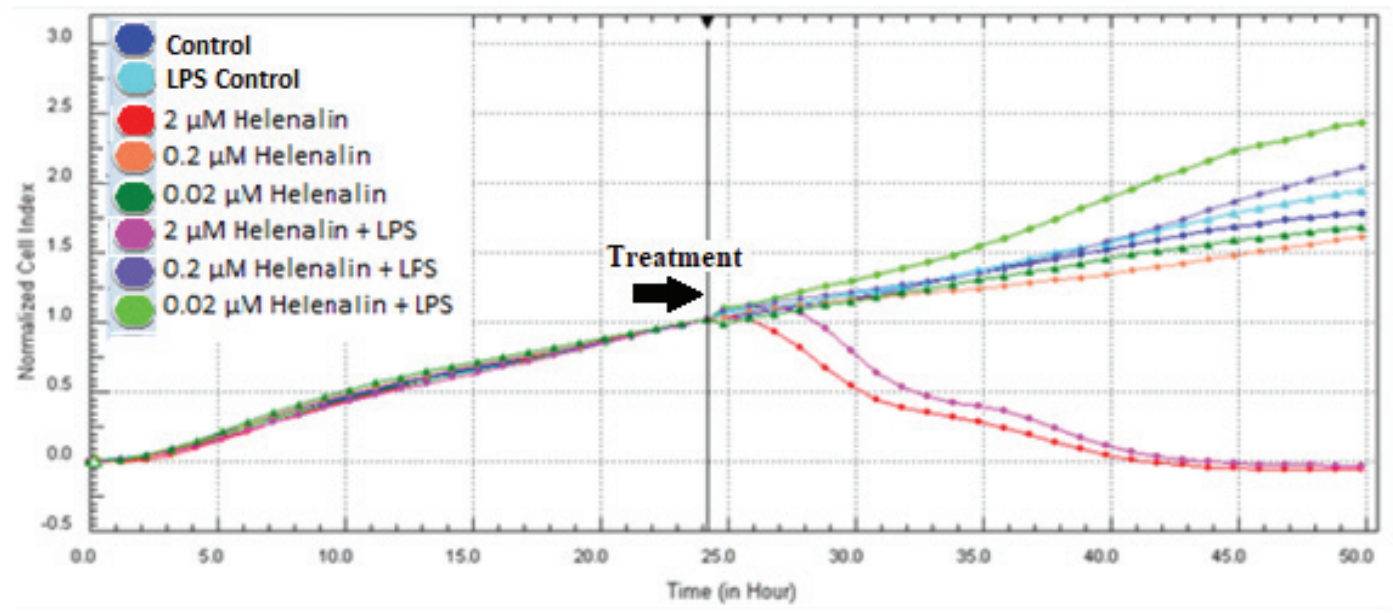

Fig. 2: Real time monitoring of anti-proliferative effects of helenalin on HaCaT cells treated with/without LPS stimulated THP-1 cells for $24 \mathrm{~h}$. Results were obtained using the RTCA DP system ( $n=6)$

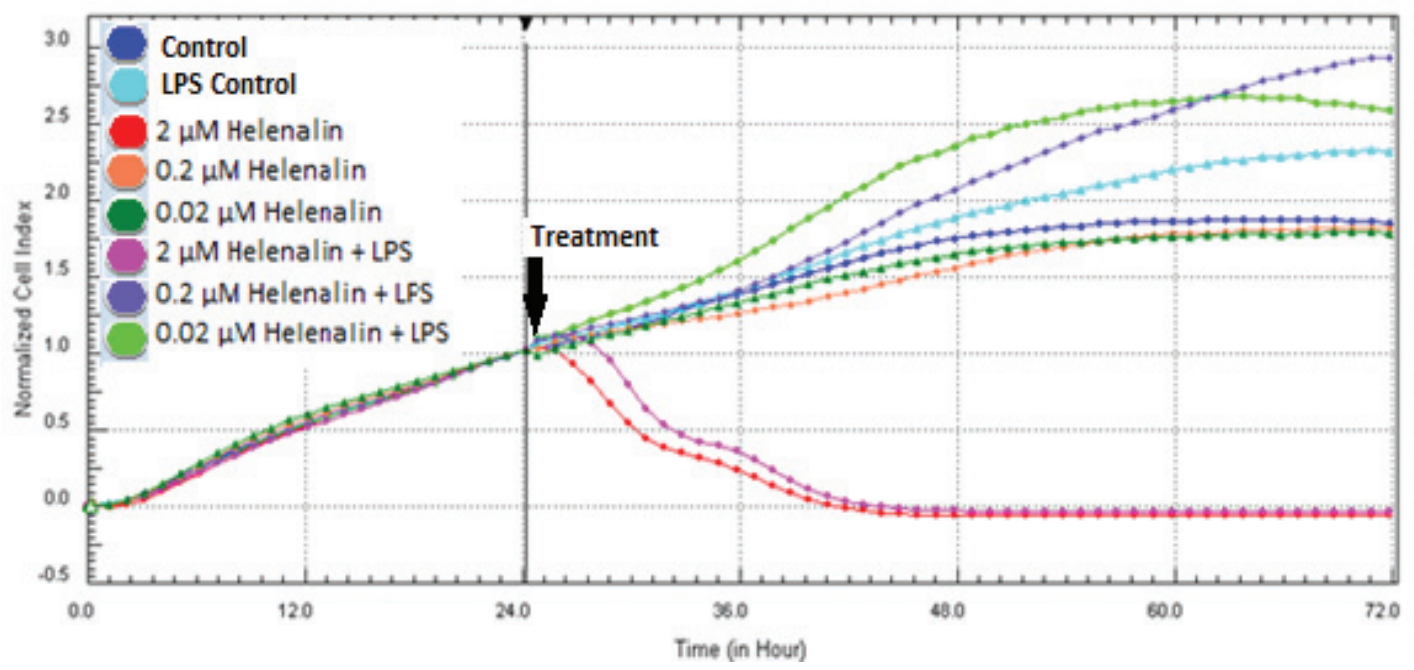

Fig. 3: Real time monitoring of anti-proliferative effects of helenalin on HaCaT cells treated with/without the medium of LPS stimulated THP-1 cells for $48 \mathrm{~h}$. Results were obtained using the RTCA DP system $(n=6)$ 
in vitro cytotoxicity to determine nontoxic Helenalin decreased cell viability at 0.2 and $0.02 \mu \mathrm{M}$ concentrations usable in vitro. In this experiment, $\mathrm{HaCaT}$ cells were treated with several concentrations of helenalin $(0.2$ and $0.02 \mu \mathrm{M}$ helenalin treated with and without inflammation conditions) for $24 \mathrm{~h}$ and $48 \mathrm{~h}$. Our findings demonstrated that helenalin decreased the cell viability, only in concentrations up to $2 \mu \mathrm{M}$ with and without inflammation conditions, according to the cell proliferation analysis (fig. 2-4).

without inflammation conditions, but the real time cell proliferation of medium control and 0.2 and $0.02 \mu \mathrm{M}$ helenalin (without inflammation) were almost the same after 48 h (fig. 3). As a result, we chose the 0.2 and $0.02 \mu \mathrm{M}$ helenalin treated with and without inflammation conditions to verify the wound healing activity in the $\mathrm{HaCaT}$ cell line.

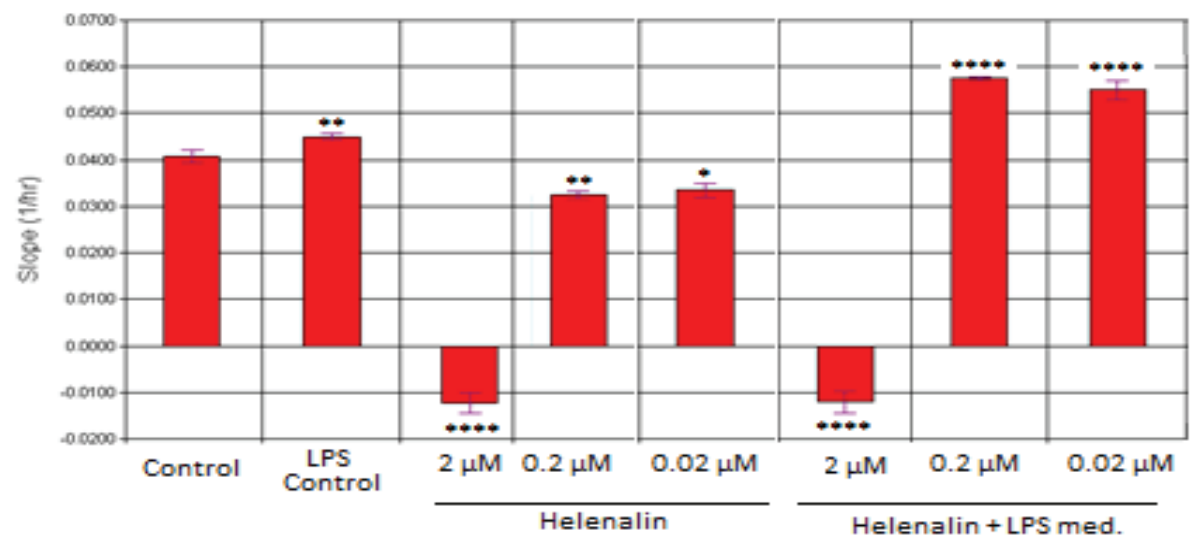

Fig. 4: Slope values of the cell proliferation curve of helenalin concentrations were calculated using the RTCA 1.2.1 Software after $24 \mathrm{~h}$ in HaCaT cells $(\mathrm{n}=6$; mean \pm standard deviation $)(\mathbf{p}<0.5 *, \mathbf{p}<0.01 * *, \mathbf{p}<0.001 * * *$ and $\mathbf{p}<0.0001 * * * *)$
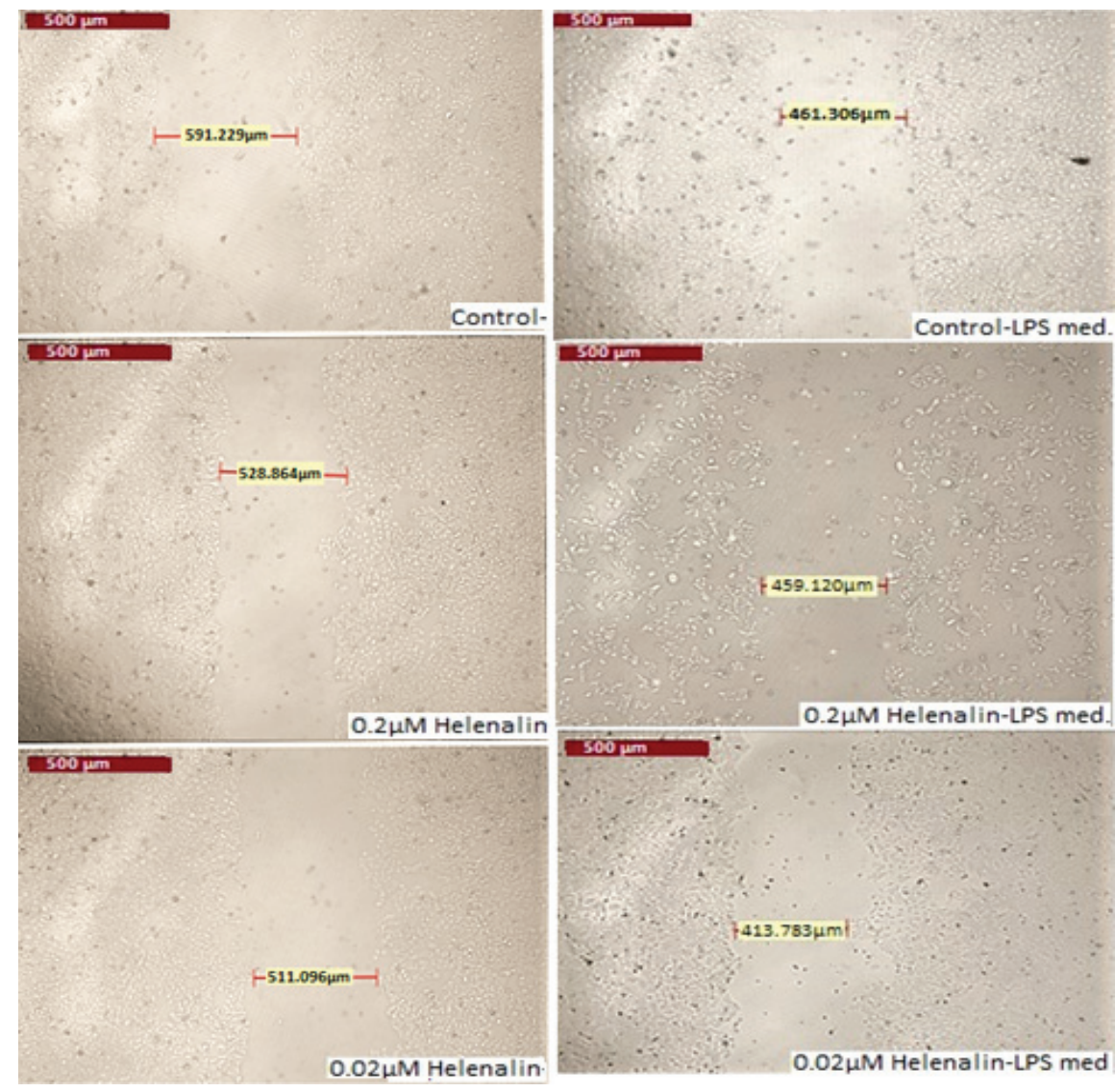

Fig. 5: Results of the scratch assay in $\mathrm{HaCaT}$ cells at $48 \mathrm{~h}$ of exposure to 0.2 and $0.02 \mu \mathrm{M}$ helenalin with/without inflammation conditions. Scratch assay was performed on digitized images of live cells taken under a Leica DM 300 inverted microscope (magnification: 100x). Control group was treated with only medium, including $0.1 \%$ DMSO. Control LPS group was treated with stimulated medium (+LPS). The wound scratch assay showed increases in migration over time 
After applying the concentrations of 0.2 and $0.02 \mu \mathrm{M}$ helenalin on the cells in LPS conditioned and non-conditioned medium, the photographs of wells were taken at $48 \mathrm{~h}$ with Leica microscope at 100x magnifications (fig. 5). Wound widths in the images were measured with the LAS Image Analysis program (fig. 6). At 48 h, greater wound closure and migration activity were observed in cultures exposed to helenalin with and without LPS compared to the LPS conditioned and non-conditioned medium control groups. It was determined that wound closure was slightly higher in the $0.02 \mu \mathrm{M}$ group than the $0.2 \mu \mathrm{M}$ group in LPS conditioned cells at $48 \mathrm{~h}$ (fig. 6).

We assessed 0.2 and $0.02 \mu \mathrm{M}$ helenalin with LPS stimulated monocyte medium following the results of the real time cell proliferation and scratch assays. The migration and slope plots of 0.2 and $0.02 \mu \mathrm{M}$ helenalin (with LPS stimulated monocytes) in the HaCaT cells according to the CI data from the RTCA DP are shown in fig. 7. Cells exposed to 0.2 and $0.02 \mu \mathrm{M}$ helenalin concentrations (in the inflammation condition) experienced significantly greater cell migration activity than those in the control group, in parallel with the real time proliferation results. The migration effect was much greater at $24 \mathrm{~h}$ for $0.02 \mu \mathrm{M}$ helenalin than $0.2 \mu \mathrm{M}$ helenalin and the control group (fig. 7A). At low concentrations of helenalin, the migration of $\mathrm{HaCaT}$ cells was significantly greater than in the control group $(\mathrm{p}<0.0001)$ (fig. 7B).

IL-8, IL-1 $\beta$, IL-6 and TNF- $\alpha$ cytokine levels were measured in HaCaT culture supernatants obtained from the scratch assay at $48 \mathrm{~h}$. The cytokine levels

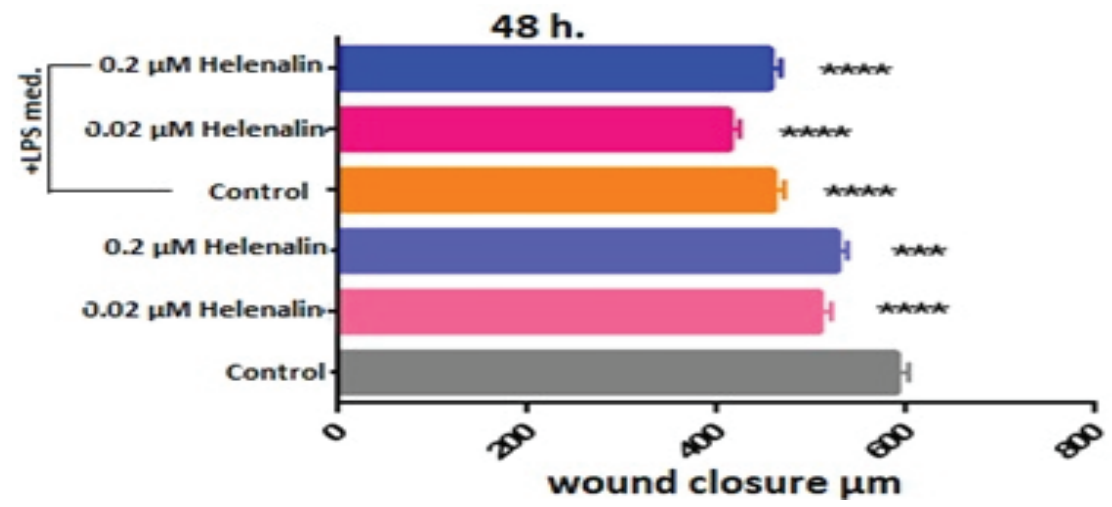

Fig. 6: Wound healing assay results were calculated according to the images shown in fig. 5. The error bars represent the standard deviations $(\mathbf{n}=\mathbf{3}, * * * \mathbf{p}<0.001$ and $\mathbf{p}<0.0001 * * * *$ compared to the medium control group)
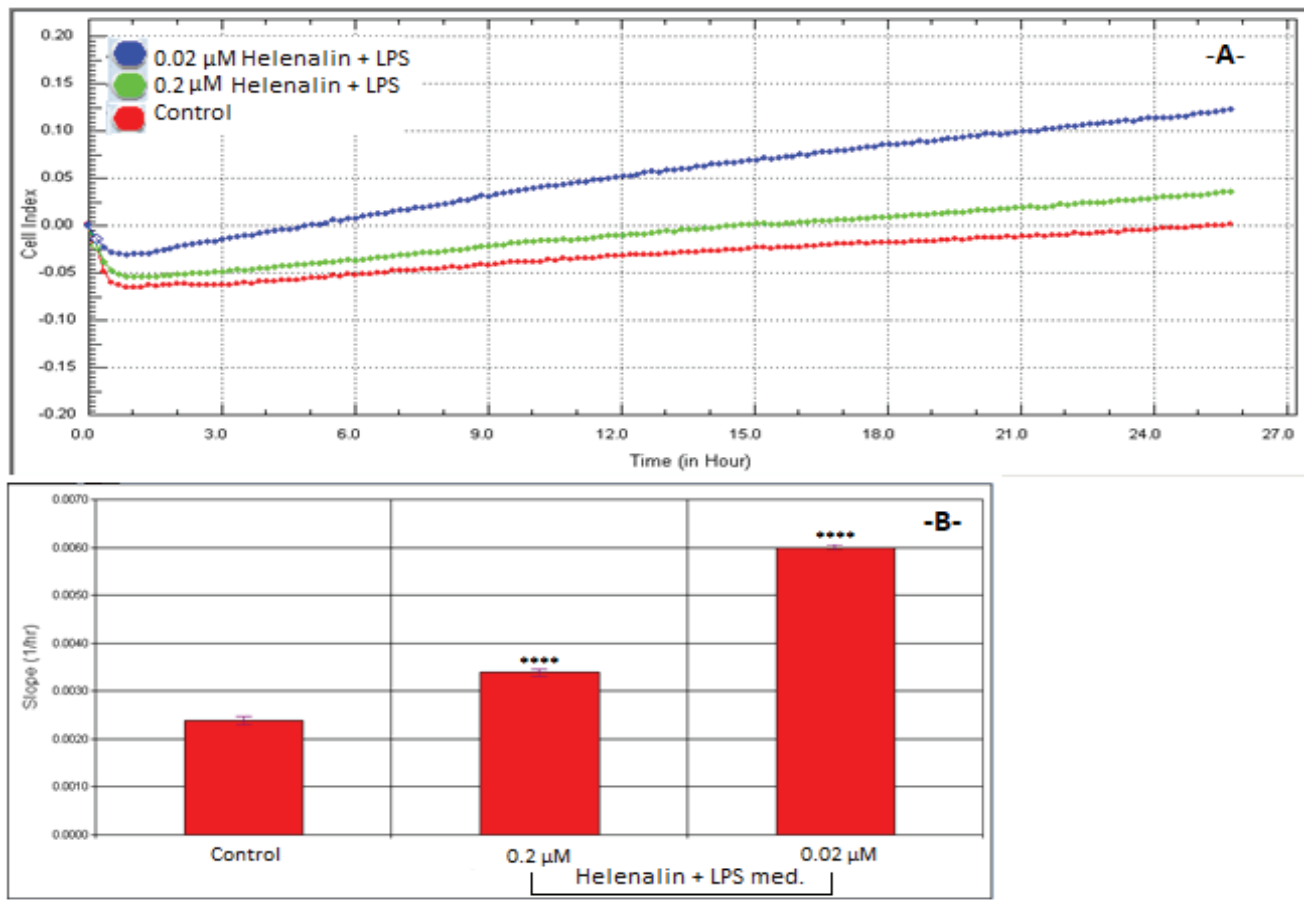

Fig. 7: (A) The migration of 0.02 and $0.2 \mu \mathrm{M}$ helenalin treated HaCaT cells with LPS stimulated THP-1 cells for $24 \mathrm{~h}$ (B) The slope of the cell migration curve was calculated using RTCA 1.2.1 software $(\mathbf{n}=6$; mean \pm standard deviation) $(\mathbf{p}<0.0001 * * * *)$ 
were analysed using flow cytometry at 0.2 and $0.02 \mu \mathrm{M}$ helenalin with and without LPS stimulated monocyte medium. In this experiment, we chose the same concentrations of helenalin as those used in the real time cell proliferation and wound healing to verify the induction of some inflammatory effects of helenalin. As shown in fig. 8, LPS alone resulted in a significant increase in the IL- 8, IL- $1 \beta$, IL- 6 and TNF- $\alpha$ cytokine production compared to the medium control group $\left(\mathrm{p}<0.0001^{* * * *}\right)$. At 0.2 and $0.02 \mu \mathrm{M}$, helenalin in medium without inflammation conditions slightly increased all levels of measured cytokines. The IL-8, IL-1 $\beta$, IL- 6 and TNF- $\alpha$ cytokine were significantly increased at $0.2 \mu \mathrm{M}$ helenalin $\left({ }^{*} \mathrm{p}<0.05, * * * \mathrm{p}<0.001\right.$ and $\mathrm{p}<0.0001 * * * *)$, but levels of IL-8 and IL-6 at $0.02 \mu \mathrm{M}$ helenalin were significantly different from the control $(* \mathrm{p}<0.05, * * * \mathrm{p}<0.001)$. Notably, in the $0.2 \mu \mathrm{M}$ and $0.02 \mu \mathrm{M}$ helenalin groups under inflammation conditions, IL-8, IL-1 $\beta$, IL-6 and TNF- $\alpha$ cytokine levels decreased compared to LPS control (only used as the medium of inflammation conditions). Especially according to the LPS control group, IL-8, IL-1 $\beta$, IL-6 and TNF- $\alpha$ cytokine levels were seen more importantly decreased in $0.02 \mu \mathrm{M}$ helenalin with inflammation conditions (fig. 8).

\section{IL-1及}

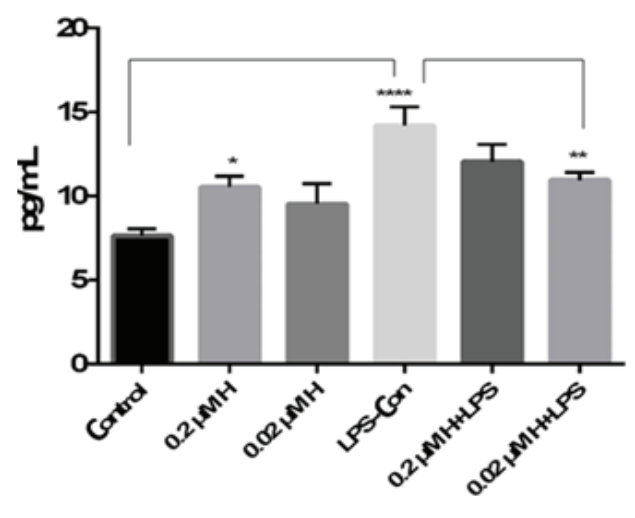

IL-8

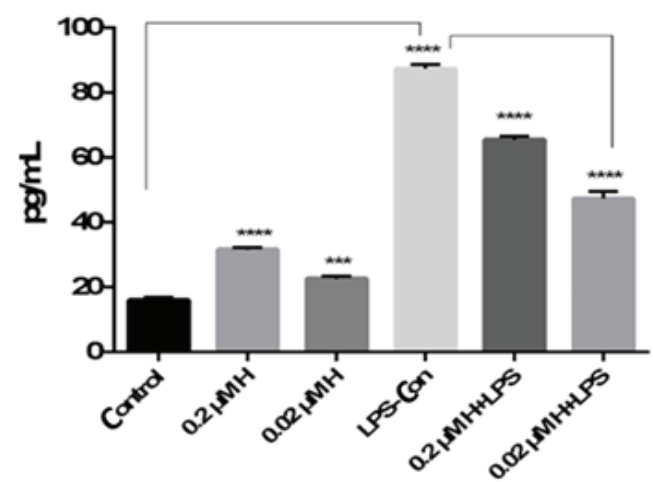

Arnica montana is a plant of the Asteraceae family and it has traditionally been used in extracts with antiseptic, anti-inflammatory, antibacterial, antisclerotic, antifungal, decongestant, wound healing and antioxidant properties ${ }^{[5,7]}$ It is suggested that the component responsible for the effects of the plant is helenalin, a sesquiterpene lactone ${ }^{[11]}$. It has been reported in several studies that helenalin selectively inhibits NF$\kappa \mathrm{B}$, thereby exhibiting anti-inflammatory effects ${ }^{[15,44,45]}$. It decreases inflammation by preventing immune cells from functioning, especially macrophages and neutrophils ${ }^{[46]}$. Also, helenalin has been demonstrated to have potent antitumor activity and the mechanisms underlying its action are entirely unexplained ${ }^{[18]}$.

In this study, we used an in vitro model, including a co culture model of wound repair with $\mathrm{HaCaT}$ cells that mimic many properties of normal epidermal keratinocytes $^{[47]}$. Firstly, we determined non-cytotoxic concentrations of helenalin then we evaluated the real time cell proliferation and migration, wound healing and anti-inflammatory effects of non-cytotoxic and slightly cytotoxic concentrations of helenalin. Keratinocytes were treated with helenalin concentrations to expose to medium obtained from monocytes stimulated with LPS to provide inflammation conditions. We evaluated these

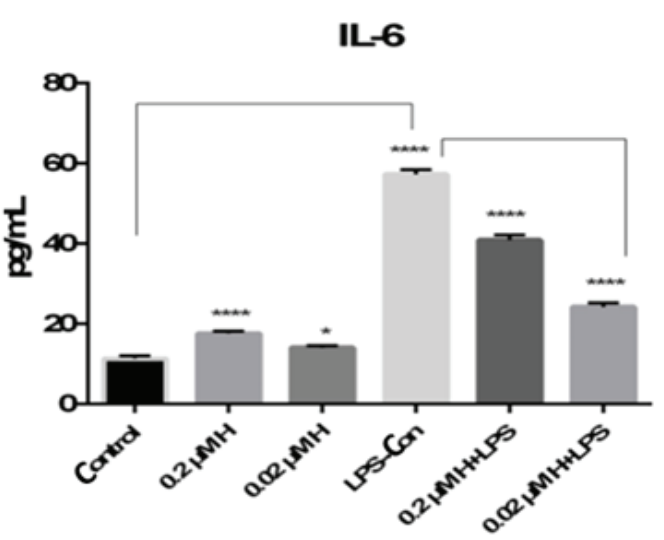

TNF- $\alpha$

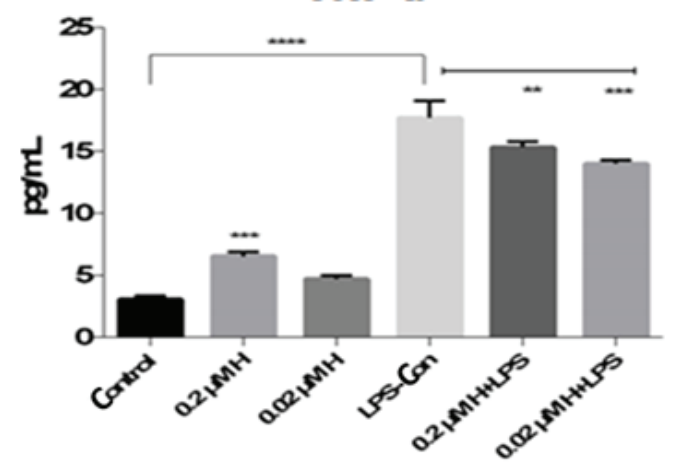

Fig. 8: Effects of Helenalin concentrations on cytokine levels in HaCaT cells. The results are the means of 3 independent experiments. The error bars represent the standard deviations $(\mathrm{n}=3, \mathrm{p}>0.05$ not significant, $* \mathbf{p}<0.05, * * \mathbf{p}<0.01, * * * \mathbf{p}<0.001$ and $\mathbf{p}<0.0001 * * * *$ compared to the medium control group) 
effects of helenalin both at conditions of inflammation and non-inflammation.

According to the real time cell analysis, 0.02 and $0.2 \mu \mathrm{M}$ helenalin in medium with LPS increased cell proliferation. The scratch test was applied to assess the wound healing activity of helenalin in keratinocyte cells. After $48 \mathrm{~h}$, the wound closure activity was determined to be greatest at 0.2 and $0.02 \mu \mathrm{M}$ helenalin in the medium with LPS. In the wound healing effect, since the results of 0.2 and $0.02 \mu \mathrm{M}$ helenalin in medium with LPS were determined to be very close to each other, the migration effects of these concentrations on keratinocyte cells were studied in real time analyses. Moreover, the $0.02 \mu \mathrm{M}$ helenalin in medium with LPS was more effective than $0.2 \mu \mathrm{M}$ helenalin in cell migration at $24 \mathrm{~h}$. In addition, cytokines were measured in supernatants collected from wound healing test groups at $48 \mathrm{~h}$ and 0.2 and $0.02 \mu \mathrm{M}$ helenalin had increased the pro inflammatory cytokines in keratinocyte cells, while under inflammation conditions, these concentrations resulted in a decrease in the IL- 8 , IL-1 $\beta$, IL- 6 and TNF- $\alpha$ cytokine levels. In LPS activated monocyte medium, the 0.2 and $0.02 \mu \mathrm{M}$ helenalin exposed cultures demonstrated significant reduction of IL- 8 , IL-1 $\beta$, IL- 6 and TNF- $\alpha$ cytokines. Notably, $0.02 \mu \mathrm{M}$ helenalin suppressed the release of all cytokines under inflammatory conditions.

No studies have thus far compared LPS stimulated and non-stimulated conditions using real time analyses of $\mathrm{HaCaT}$ cell proliferation and migration, wound healing scratch test and anti-inflammatory effects of the helenalin nontoxic concentrations.

Cytotoxic effects of helenalin at toxic concentrations have been determined in cancer cell lines. The concentration of 4 and $6 \mu \mathrm{M}$ helenalin significantly reduced cell viability in a human renal cell line ${ }^{[13]}$. Also helenalin was shown to significantly decrease cell viability at concentrations $\geq 0.19 \mu \mathrm{M}$ in THP-1 monocytes, $\geq 0.75 \mu \mathrm{M}$ in Jurkat $\mathrm{T}$ cells and $\geq 0.38 \mu \mathrm{M}$ in peripheral blood mononuclear cells ${ }^{[48]}$.

Keratinocytes represent the most significant cell population of the human epidermis, involved in both physical and first line immune protection of the host. Keratinocytes are themselves capable of amplifying an inflammatory signal by recruiting inflammatory cells and by producing inflammatory mediators. Upon stimulation by exogenous factors such as LPS, keratinocytes actively secrete large amounts of cytokines, including IL- $1 \alpha$, IL- $\beta$, IL- 6 , interferons and TNF- $\alpha$. IL-1 activates NF- $\kappa$ B. NF- $\kappa$ B is primarily composed of proteins with a molecular mass of 50 (p50) and $65 \mathrm{kDa}(\mathrm{p} 65)$ and is retained in the cytoplasm by inhibitor of nuclear factor kappa $B(I \kappa B \alpha)$. In our results, we used low concentrations of helenalin as an NF- $\kappa \mathrm{B}$ inhibitor and it decreased the secretion of cytokines from cells via inactivation of the NF- $\kappa$ B under inflammatory conditions. In a study of the stimulation of Jurkat $\mathrm{T}$ cells, 70Z/3 and Mo7/E cells with TNF- $\alpha$ and LPS, helenalin at micro molar concentrations was reported to inhibit NF- $\mathrm{kB}$ activation ${ }^{[49]}$.

In this study, we created an alternative co culture model of unexposed immune cells to create acute inflammation conditions. Acute inflammation is a relatively brief period and may be followed by an immune response characterized by the activation of immune cells ${ }^{[23]}$. LPS was used to induce the release of inflammatory cytokines from THP-1 cells and HaCaT cells were treated with helenalin concentrations prepared with or without THP-1 cells stimulated by LPS. The stable LPS in the medium may also have induced the release of inflammatory cytokines from $\mathrm{HaCaT}$ cells. One study reported the $\mathrm{HaCaT}$ cells increased the release of IL-1 $\beta$ and TNF- $\alpha$ when they were stimulated with LPS ${ }^{[22]}$. In another study, keratinocytes secreted pro inflammatory cytokines when they encountered a sensitizing agent in the HaCaT and THP-1 co culture model ${ }^{[50]}$.

IL-8, IL-1 $\beta$, IL-6 and TNF- $\alpha$ are important pro inflammatory cytokines and have important roles in wound healing ${ }^{[51]}$. IL- $1 \beta$, known to activate $N F-\kappa B$, is effective in keratinocyte proliferation and migration. IL-6, which has a mitogenic effect on keratinocytes, is critical in the initiation of the wound healing response. Multiple studies have demonstrated that IL- 6 decreases TNF- $\alpha$ production, meaning it is considered as both pro inflammatory and anti-inflammatory ${ }^{[52]}$. IL-8 is known to contribute to re-epithelialization by increasing keratinocyte migration and proliferation ${ }^{[21,53]}$.

In cell stimulation studies in which the $\mathrm{HaCaT}$ cell line was exposed to multiple LPS concentrations, it was observed that IL-1 $\beta$ and TNF increased the most in the $100 \mathrm{ng} / \mathrm{ml}$ LPS stimulated group ${ }^{[22]}$. In cases of inflammation, TNF- $\alpha$ is the first stimulated cytokine ${ }^{[54]}$. In our study, IL-1 $\beta$ and TNF levels were similar in the control group stimulated with $100 \mathrm{ng} / \mathrm{ml}$ LPS. In our study, the decrease seen in both IL- $1 \beta$ and TNF- $\alpha$ in the $\mathrm{HaCaT}$ cells treated with $0.02 \mu \mathrm{M}$ helenalin was due to an anti-inflammatory effect.

In a study investigating the effects of helenalin on alcohol induced liver injury, serum transforming growth factor beta 1 (TGF- $\beta 1$ ), TNF- $\alpha$, IL-6 and IL- $1 \beta$ levels, which 
were significantly higher in the model group compared to the control, decreased with helenalin treatment. According to the cytokine results obtained from our study, helenalin reduced cytokine production and had a positive effect on the wound healing processes ${ }^{[52]}$. Finally, L929 fibroblast and HaCaT cell lines were found to have higher wound closure in the group with high IL-8 levels with LPS stimulation ${ }^{[55]}$.

In conclusion, helenalin has been found to decrease the production of inflammatory cytokines, especially under inflammatory conditions and increase wound closure by increasing cell proliferation and migration. However, we believe additional molecular employing different experimental models studies are necessary to further explore these phenomena.

\section{Acknowledgements:}

This study has been produced from master's thesis of Sevda Nur Yuksel, which was conducted under the advisor Miris Dikmen and the second advisor Zerrin Canturk. All authors have read and approved the final version of the manuscript. HaCaT cells were supplied from Prof. Dr. Arzu Onay Besikci from Ankara University, Pharmacy Faculty.

\section{Conflict of Interests:}

None of the authors had any conflict of interest that could affect the performance of the work or the interpretation of the data.

\section{REFERENCES}

1. Berk A, Dokumaci AH, Kaymaz MB. Medicinal plants used in wound healing and diabetic wound treatment. J Health Sci 2015;24:185-92.

2. Deniz C. Comparison of sweetgum oil (Liquidambar orientalis), a plant resin in wound healing and pomades containing collagenase. Specialty Thesis in Medicine. Kahramanmaras: Sutcu Imam University; 2010.

3. Battaglia TM, Masson JF, Sierks MR, Beaudoin SP, Rogers $\mathrm{J}$, Foster KN, et al. Quantification of cytokines involved in wound healing using surface plasmon resonance. Anal Chem 2005;77:7016-23.

4. Er S, Dikmen M. Camellia sinensis increased apoptosis on U2OS osteosarcoma cells and wound healing potential on NIH3T3 fibroblast cells. Cytotechnology 2017;69(6):901-14.

5. Macedo SB, Ferreira LR, Perazzo FF, Carvalho JT. Antiinflammatory activity of Arnica montana $6 \mathrm{cH}$ : preclinical study in animals. Homeopathy 2004;93(2):84-7.

6. Lass C, Vocanson M, Wagner S, Schempp CM, Nicolas JF, Merfort I, et al. Anti-inflammatory and immune-regulatory mechanisms prevent contact hypersensitivity to Arnica montana L. Exp Dermatol 2008;17(10):849-57.

7. Baser KHC. Mountain ox (Arnica montana L.). Bagbahce 2016;63:26-27.

8. Ahmad MA, Saeed FA, Mehjabeen Jahan N. Neuro- pharmacological and analgesic effects of Arnica montana extract. Int J Pharm Pharm Sci 2013;5(4):590-3.

9. Staneva J, Denkova P, Todorova M, Evstatieva L. Quantitative analysis of sesquiterpene lactones in extract of Arnica montana L. by $1 \mathrm{H}$ NMR spectroscopy. J Pharm Biomed Anal 2011;54(1):94-9.

10. Purkait B, Sharma A. Identification and characterization of medicinally active Ingredient of endangered plant Arnica Montana. Int J Pharm Chem Anal 2015;2(2):59-64.

11. Rodrigues DD, Luna SP, Brondani JT, Minto BW. Comparison of morphine, ketoprofen and Arnica montana 6x and 30x per oral transmucosal or subcutaneous route for control of postoperative pain in cats subjected to hysterectomy with bilateral salpingo-oophorectomy. Cienc Rural 2016;46(2):3305.

12. Supornsilchai V, Soder O, Svechnikov K. Sesquiterpene lactone helenalin suppresses Leydig and adrenocortical cell steroidogenesis by inhibiting expression of the steroidogenic acute regulatory protein. Reprod Toxicol 2006;22(4):631-5.

13. Jang JH, Iqbal T, Min KJ, Kim S, Park JW, Son EI, et al. Helenalin-induced apoptosis is dependent on production of reactive oxygen species and independent of induction of endoplasmic reticulum stress in renal cell carcinoma. Toxicol In Vitro 2013;27(2):588-96.

14. Auld CA, Hopkins RG, Fernandes KM, Morrison RF. Novel effect of helenalin on Akt signaling and Skp2 expression in 3T3-L1 preadipocytes. Biochem Biophys Res Commun 2006;346(1):314-20.

15. Tornhamre S, Schmidt TJ, Nasman-Glaser B, Ericsson I, Lindgren JA. Inhibitory effects of helenalin and related compounds on 5-lipoxygenase and leukotriene $\mathrm{C} 4$ synthase in human blood cells. Biochem Pharmacol 2001;62(7):903-11.

16. Gautam R, Jachak SM. Recent developments in antiinflammatory natural products. Med Res Rev 2009;29(5):767820.

17. Chadwick M, Trewin H, Gawthrop F, Wagstaff C. Sesquiterpenoids lactones: benefits to plants and people. Int J Mol Sci 2013;14(6):12780-805.

18. Drogosz J, Janecka A. Helenalin-a sesquiterpene lactone with multidirectional activity. Curr Drug Targets 2019;20(4):44452.

19. Seo MD, Kang TJ, Lee CH, Lee AY, Noh M. HaCaT keratinocytes and primary epidermal keratinocytes have different transcriptional profiles of cornified envelopeassociated genes to $\mathrm{T}$ helper cell cytokines. Biomol Ther 2012;20(2):171-6.

20. Hofmann U, Priem M, Bartzsch C, Winckler T, Feller KH. A sensitive sensor cell line for the detection of oxidative stress responses in cultured human keratinocytes. Sensors 2014;14(7):11293-307.

21. Wedler J, Daubitz T, Schlotterbeck G, Butterweck V. In vitro anti-inflammatory and wound-healing potential of a Phyllostachys edulis leaf extract identification of isoorientin as an active compound. Planta Med 2014;80(18):1678-84.

22. Cheng HM, Hsiang CY, Chen GW, Wu SL, Chen JC, Huang $\mathrm{CY}$, et al. Inhibition of lipopolysaccharide-induced interleukin1 beta and tumor necrosis factor-alpha production by menthone through nuclear factor-kappaB signaling pathway in $\mathrm{HaCat}$ cells. Chin J Physiol 2008;51(3):160-6.

23. Di Caprio R, Lembo S, Di Costanzo L, Balato A, Monfrecola G. Anti-inflammatory properties of low and high doxycycline doses: an in vitro study. Mediators Inflamm 2015;1-11.

24. Ubanako P, Xelwa N, Ntwasa M. LPS induces inflammatory 
chemokines via TLR-4 signalling and enhances the Warburg effect in THP-1 cells. PLoS One 2019;14(9):e0222614.

25. Shah YM, Ma X, Morimura K, Kim I, Gonzalez FJ. Pregnane $\mathrm{X}$ receptor activation ameliorates DSS-induced inflammatory bowel disease via inhibition of NF- $\mathrm{kB}$ target gene expression. Am J Physiol Gastrointest Liver Physiol 2007;292(4):G111422.

26. Qin Z. The use of THP-1 cells as a model for mimicking the function and regulation of monocytes and macrophages in the vasculature. Atherosclerosis 2012;221(1):2-11.

27. Tucureanu MM, Rebleanu D, Constantinescu CA, Deleanu M, Voicu G, Butoi E, et al. Lipopolysaccharide induced inflammation in monocytes/macrophages is blocked by liposomal delivery of Gi-protein inhibitor. Int J Nanomedicine 2018;13:63-76.

28. Albrahim T, Alnasser MM, Al-Anazi MR, ALKahtani MD, Alkahtani S, Al-Qahtani AA. Potential anti-inflammatory and anti-apoptotic effect of Coccinia grandis plant extract in LPS stimulated-THP-1 cells. Environ Sci Pollut Res 2020;27:21892-904.

29. Yang H, Liu C, Yang D, Zhang H, Xi Z. Comparative study of cytotoxicity, oxidative stress and genotoxicity induced by four typical nanomaterials: the role of particle size, shape and composition. J Appl Toxicol 2009;29(1):69-78.

30. Engur S, Dikmen M, Ozturk Y. Comparison of antiproliferative and apoptotic effects of a novel proteasome inhibitor MLN2238 with bortezomib on K562 chronic myeloid leukemia cells. Immunopharmacol Immunotoxicol 2016;38(2):87-97.

31. Kaya-Tilki E, Dikmen M, Ozturk Y. Effects of DNMT and HDAC inhibitors (RG108 and Trichostatin A) on NGF-induced neurite outgrowth and cellular migration. Int $\mathrm{J}$ Pharmacol 2016;12(4):351-60.

32. Bird C, Kirstein S. Real-time, label-free monitoring of cellular invasion and migration with the xCELLigence system. Nat Methods 2009;6(8):5-6.

33. Solly K, Wang X, Xu X, Strulovici B, Zheng W. Application of real-time cell electronic sensing (RT-CES) technology to cellbased assays. Assay Drug Dev Technol 2004;2(4):363-72.

34. Urcan E, Haertel U, Styllou M, Hickel R, Scherthan H, Reichl FX. Real-time xCELLigence impedance analysis of the cytotoxicity of dental composite components on human gingival fibroblasts. Dent Mater 2010;26(1):51-8.

35. Dikmen M, Canturk Z, Engur S, Kaya Tilki E. Inhibitory effects of secondary metabolites of halotolerant Aspergillus terreus on angiogenesis. Biomed Res 2017;28(8):3613-8.

36. Engur S, Dikmen M. The evaluation of the anti-cancer activity of ixazomib on Caco2 colon solid tumor cells, comparison with bortezomib. Acta Clin Belg 2017;72(6):391-8.

37. Liang CC, Park AY, Guan JL. In vitro scratch assay: a convenient and inexpensive method for analysis of cell migration in vitro. Nat Protoc 2007;2(2):329-33.

38. Jonkman JE, Cathcart JA, Xu F, Bartolini ME, Amon JE, Stevens KM, et al. An introduction to the wound healing assay using live-cell microscopy. Cell Adh Migr 2014;8(5):440-51.

39. Fronza M, Heinzmann B, Hamburger M, Laufer S, Merfort I. Determination of the wound healing effect of Calendula extracts using the scratch assay with $3 \mathrm{~T} 3$ fibroblasts. J Ethnopharmacol 2009;126(3):463-7.
40. Limame R, Wouters A, Pauwels B, Fransen E, Peeters $\mathrm{M}$, Lardon $\mathrm{F}$, et al. Comparative analysis of dynamic cell viability, migration and invasion assessments by novel realtime technology and classic endpoint assays. PLoS One 2012;7(10):e46536.

41. Dikmen M, Canturk Z, Tilki EK, Engur S. Evaluation of antiangiogenic and antimetastatic Effects of Penicillium chrysogenum Secondary Metabolites. Indian J Pharm Sci 2017;79(1):49-57.

42. Chen R, Lowe L, Wilson JD, Crowther E, Tzeggai K, Bishop $\mathrm{JE}$, et al. Simultaneous quantification of six human cytokines in a single sample using microparticle-based flow cytometric technology. Clin Chem 1999;45(9):1693-4.

43. Canturk Z. Compared effects of azole antifungals on cytokine production of THP-1 cells activated by Candida albicans. Marmara Pharm J 2016;20(3):288-92.

44. Woerdenbag HJ, Merfort I, Schmidt TJ, Passreiter CM, Willuhn G, Van Uden W, et al. Decreased helenalin-induced cytotoxicity by flavonoids from Arnica as studied in a human lung carcinoma cell line. Phytomedicine 1995;2(2):127-32.

45. Berges C, Fuchs D, Opelz G, Daniel V, Naujokat C. Helenalin suppresses essential immune functions of activated CD4+ $\mathrm{T}$ cells by multiple mechanisms. Mol Immunol 2009;46(15):2892-901.

46. May P. Arnica flower $\mathrm{CO} 2$ extract: Approved efficacy in topical treatment. Cosmet Sci Technol 2013:1-6.

47. Perfetto B, Stellavato A, Melito A, De Gregorio V, Cammarota M, Giuliano M. A time-lapse approach to examine chromium and nickel effects on wound healing in vitro. J Immunotoxicol 2012;9(4):392-400.

48. Zwicker P, Schultze N, Niehs S, Albrecht D, Methling K, Wurster $\mathrm{M}$, et al. Differential effects of Helenalin, an antiinflammatory sesquiterpene lactone, on the proteome, metabolome and the oxidative stress response in several immune cell types. Toxicol In Vitro 2017;40:45-54.

49. Lyss G, Schmidt TJ, Merfort I, Pahl HL. Helenalin, an anti-inflammatory sesquiterpene lactone from Arnica, selectively inhibits transcription factor NF- $\mathrm{KB}$. Biol Chem 1997;378(9):951-62.

50. Hennen J, Blomeke B. Keratinocytes improve prediction of sensitization potential and potency of chemicals with THP-1 cells. Altern Anim Exp 2017;34(2):279-88.

51. Turabelidze A, Dipietro LA. Inflammation and wound healing. Endod Topics 2011;24(1):26-38.

52. Lin X, Zhang S, Huang R, Wei L, Tan S, Liang S, et al. Helenalin attenuates alcohol-induced hepatic fibrosis by enhancing ethanol metabolism, inhibiting oxidative stress and suppressing HSC activation. Fitoterapia 2014;95:203-13.

53. Takada K, Komine-Aizawa S, Hirohata N, Trinh QD, Nishina A, Kimura H, et al. Poly I: C induces collective migration of HaCaT keratinocytes via IL-8. BMC immunol 2017;18(1):110 .

54. Van der Poll T. Immunotherapy of sepsis. Lancet Infect Dis 2001;1(3):165-74.

55. Walter MN, Wright KT, Fuller HR, MacNeil S, Johnson WE. Mesenchymal stem cell-conditioned medium accelerates skin wound healing: an in vitro study of fibroblast and keratinocyte scratch assays. Exp Cell Res 2010;316(7):1271-81. 